\title{
Review of Nondestructive Testing Technology for Compaction Quality of Soil
}

\author{
Zhengjun WANG \\ Institute of hydraulic and electric engineering \\ Heilongjiang University, China \\ E-mail: wzjsir@163.com
}

\author{
Xinxin LI \\ Institute of hydraulic and electric engineering \\ Heilongjiang University, China \\ E-mail: 595585058@qq.com
}

\begin{abstract}
Compaction index is the key to ensure quality, the compaction degree detection has a lot of kinds of methods, and some of these methods are time-consuming, some operations are very complex, some precision are not enough, so we urgently need a fast and nondestructive method to measure the compaction of soil. This paper presents the characteristic and applications of these nondestructive methods which will be useful for the selection of detection methods.
\end{abstract}

Keywords-compaction degree; nodestructive testing; modulus

\section{INTRODUCTION}

Currently, detection and evaluation of compaction degree is mainly used by destructive and non-destructive testing method. Cutting ring method may produce deviation in sampling process and it is time-consuming; sand-cone method is the most common method in the test of subgrade, but the sand-cone method has some shortcomings that the operation process and data will be affected by human factors. Dynamic Cone Penetrometer (DCP) infers compaction through the establishment of the number of thump and density curve, but the detection is easily affected by the height of the hammer and the strength of hammer. The number of selected points is limited, so the representation of the points is poor. Therefore, this kind of detection can not meet the requirements of nondestructive, fast and high precision.

The most popular nondestructive testing method controlling soil compaction is to measure the density of the soil with a nuclear density gauge. The use of nuclear density gauge is very inconvenient because it contains radioactive materials which do harm to human. Therefore, we need a nondestructive testing method to detect the degree of compaction.

\section{Nondestructive Testing}

\section{A. Ray Tracing Method}

Nuclear Density Gauge is equipment which used to measure the density and water content of the soil by using radioactive elements. It can detect soil, gravel, soil and stone mixture, asphalt mixture and other materials. This method is so convenient and rapid that a point is completed only need two minutes. The disadvantage of this method is that radioactive substances are harmful to human body, and the radioactive source will decay which means the accuracy is not enough.

\section{B. Electromagnetic Induction Testing}

Ground Penetrating Radar (GPR) is a non-invasive geophysical tool used for imaging the shallow subsurface with high image resolution. It uses radio waves in order to detect contrasts in the dielectric properties of subsurface media [1]. When the electromagnetic wave is encountered in the underground target of electromagnetic wave difference, a part of the electromagnetic wave transmission over the target body, the other part will be reflected back and returned to the ground by the receiving antenna. According to the radar received waveform, intensity and two-way travel time and the pavement structure, the space position of the underground object can be inferred, and the geometric shape can be achieved. This method is characterized by rapid, nondestructive, continuous detection, and real-time imaging to show the subsurface structure profile. Due to the high detection accuracy and high efficiency, Ground Penetrating Radar subject to the attention of some industries.

Soil Density Gauge (SDG) is a kind of equipment based on the principle of electromagnetism, and it can reflect the density and moisture by the change of the electrochemical impedance of the material matrix through the electromagnetic induction field. It reflects the density and moisture by the change of the electrochemical impedance of the material matrix by the electromagnetic induction field.

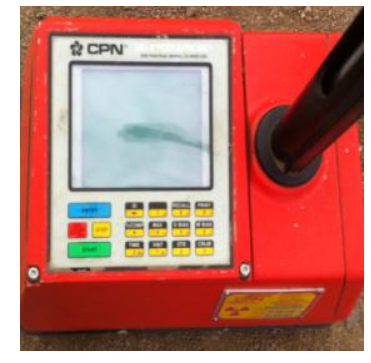

Figure 1. Nuclear density gauge

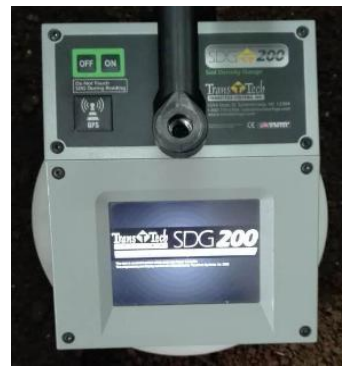

Figure 2. SDG

\section{Elastic Wave Testing}

When the filling density change in the process of propagation of Rayleigh surface wave, dispersion phenomenon will appear, therefore, it provides a favorable seismic and geological condition for the detection of the compaction degree of subgrade soil. Rayleigh wave method has many advantage, the instrument is portable and easy to operate; the results can be displayed on the spot. At present there are some problems such as timing error caused by 
different exciting force, different excitation modes have different wave velocities.

Direct wave method is mainly used to establish an empirical formula for the correlation between shear wave velocity and dry density of soil, according to this formula, the dry density of the soil can be obtained, so as to compaction.

\section{Transient Detection}

Soil Stiffness Gauge (SSG) is a new device that measures the stiffness of compacted granular materials. The device acts as a miniature plate load test. The SSG imparts very small displacements to the soil at 25 steady state frequencies between 100 and 196Hz.the stiffness is determined by the ratio of the force to displacement. The displacement is proportional to the outside radius of the SSG, and the Young's Modulus and Poisson's ratio of the soil [2]. Preliminary studies indicate the SSG can be used to control the compaction of soil for roadway construction, particularly in trenches, embankments, and behind abutment walls.

Among the deflection based devices, the falling weight deflectometer (FWD) is the most widely used and, actually, is considered as a standard test for pavement evaluation.[34] FWD control the hammer lifting and then drop through a computer, The hammer produced load on the pavement, the displacement sensor can be measured by the load generated deformation.

Different types of devices have been developed in the world and, over the years, they have experienced increasing popularity due to their light weight, quick measurements and high performance, compared to the conventional static tests (e.g., static plate test, CBR test and Benkelman beam).[5]

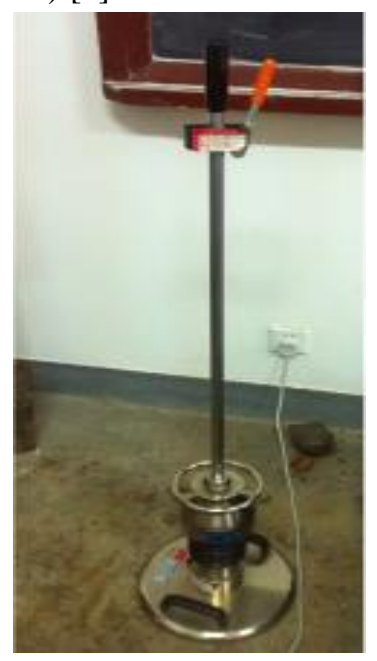

Figure 3. PFWD

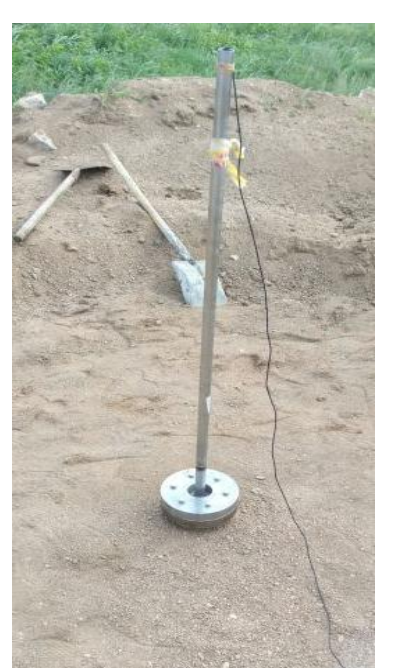

Figure 4. FBT
Portable Falling Weight Deflectometer(PFWD)is a foundation of the filling surface (including subgrade, foundation and ground, etc.) dynamic load capacity test equipment. The working principle of the PFWD is to simulate the dynamic stress of the subgrade under the dynamic load of the vehicle. In this case, the accuracy of the test is reliable. Compared with the traditional Backman beam method, PFWD is convenient and rapid, and it can be used for long distance and continuous measurement. Now this method has been applied to the detection of compaction quality of high railway bed.

Falling Ball Tester for Mechanical Properties of Geomaterial (FBT) mainly includes the falling sphere, acceleration sensor, amplifier, $\mathrm{AD}$ acquisition card, host components. Its principle is through the metal of a rigid sphere whereabouts, using Hertz contact theory, and the collision process is divided into two parts, namely compression process and springback process. The deformation modulus is calculated by the compression part of the contact time, the elastic modulus is calculated by the contact time of the spring back.

Compression modulus of deformation

$$
E_{c}=\frac{\kappa \cdot\left(1-\mu_{2}^{2}\right) \cdot m_{1} E_{1}}{0.0719 E_{1} \cdot \sqrt{R_{1} v_{0}} \cdot T_{c c}^{2.5}-m_{1}\left(1-\mu_{1}^{2}\right)}
$$

Where $\mathcal{K}_{\text {is }}$ the corresponding correction coefficient

$T_{c-c}$ is the corresponding contact time

$$
T_{c c}=2 T_{c-c}
$$

$T_{c c}$ is the compression time of the collision between the sphere and the rock mass.

Elastic modulus of deformation

$$
E_{u r}=\frac{\kappa \cdot\left(1-\mu_{2}^{2}\right) \cdot m_{1} E_{1}}{0.0719 E_{1} \cdot \sqrt{R_{1} v_{0}} \cdot T_{c r}^{2.5}-m_{1}\left(1-\mu_{1}^{2}\right)}
$$

Where $\kappa_{\text {is the corresponding correction coefficient }}$

$T_{c r}$ is the corresponding contact time

By testing the deformation modulus, the Backman deflection can be calculated. The test depth of FBT is roughly $20-30 \mathrm{~cm}$, but the test results are affected by the viscosity, strain level and loading velocity, particle size and so on. It is suitable for silt, sand, cement and so on, but it is not suitable for the inspection of the stone.

Compaction Meter is a method for evaluating and controlling the quality of subgrade compaction by using the dynamic response information of vibratory roller in the rolling process. The dynamic response of the sensor is tested by loading on the vibration wheel, and the continuous control in the rolling process is realized.

$$
C M V \propto \frac{A_{1}\left(F_{1}\right)}{A_{0}\left(F_{0}\right)}
$$

CMV is compaction meter value

$\mathrm{A} 1(\mathrm{~F} 1)$ is the first harmonic dynamic response signal signal 
Due to different types of vibration roller in different working conditions, the need to choose different working frequency, compaction meter work should be the frequency selection switch to the same position with the frequency of vibration mill. When the compaction meter is used as the main means of quality inspection, it is very important to determine the compaction parameters through the roller compaction test.

In conclusion: the Nuclear Density Gauge has certain radiation risk, the transmission method also has certain damage; Ground Penetrating Radar is sensitive to the influence of water content, but the effect of compaction test is not good; Rayleigh wave test needs so a large number of measurement points that the test speed is slow; due to the presence of springboard phenomenon, PFWD method in the rigid semi-rigid material determination accuracy is not enough; and the application of Direct wave method is not very extensive now, so, the accuracy needs to be studied.

\section{COMPaCtion Detection TeChNOLOGY APPLICATIONS}

TABLE I. COMPARISON OF THE APPliCABLE SCOPE OF THE FIELD DENSITY DETECTION METHOD

\begin{tabular}{|l|l|}
\hline test method & Application \\
\hline $\begin{array}{l}\text { Nuclear } \\
\text { density gauge }\end{array}$ & $\begin{array}{l}\text { Suitable for the determination of the density and moisture } \\
\text { content of subgrade or pavement materials should not be } \\
\text { used as an arbitration test or acceptance test. }\end{array}$ \\
\hline $\begin{array}{l}\text { Ground } \\
\text { Renetrating }\end{array}$ & $\begin{array}{l}\text { Applied to shallow geological structure, lithology } \\
\text { detection can also be used in dam detection. }\end{array}$ \\
\hline $\begin{array}{l}\text { Rayleigh } \\
\text { surface wave, }\end{array}$ & $\begin{array}{l}\text { It can be used for the detection of underground air } \\
\text { conditioning and buried objects, roads, airport runway } \\
\text { and other non-destructive testing and earth rock dam } \\
\text { crack detection. }\end{array}$ \\
\hline SDG & $\begin{array}{l}\text { Suitable for the compaction of silt, clay and sand } \\
\text { cuitable for railway, Airport Road, port, highway } \\
\text { bearing capacity of the subgrade or foundation for rapid } \\
\text { detection. }\end{array}$ \\
\hline PFWD & $\begin{array}{l}\text { Suitable for silt, sand, gravel soil, cement and so on, does } \\
\text { not apply to the stone. }\end{array}$ \\
\hline FBT & $\begin{array}{l}\text { Applications include subgrade, subbase, base, lime, } \\
\text { cement, fly-ash and polymer stabilized materials, cement- } \\
\text { treated and rehabilitated bases, large particle aggregate } \\
\text { bases, as well as underground utility backfills.[6] }\end{array}$ \\
\hline SSG
\end{tabular}

\section{DETECTION INDEX}

In the subgrade, compaction quality detection index can be divided into physical index, strength index and deformation index. Physical indicators include compaction, relative density, porosity and gas content and so on, the compaction is the most widely used physical index. In the above mentioned methods, in addition to SDG in the measurement can be directly read the value of the degree of compaction, other equipment $\mathrm{s}$ are indirectly measured compaction. But for the gravel soil, the degree of compaction is not any significance; in the construction often use the settlement value as the detection index.

The degeneration index mainly refers to the modulus of deformation, the coefficient of foundation $\mathrm{K}_{30}$, among them, the foundation coefficient is mainly used in Japan, and there are some places where the Backman beam deflection is a kind of deformation index. PFWD method and FBT although the principle is not the same, but it can be concluded that the deflection value and dynamic modulus, FBT can even calculate $K_{30}$. The traditional method for detecting deflection is Backman beam method, but its operation process is not simple, so it is easy to produce deviation.

Dynamic modulus can be used as a detection index, especially in the detection of highway, in February 1997, Germany promulgated and implemented the German Railway Construction in light of drop hammer machine using the specified (NGT39). The standard shows that the dynamic deformation modulus and the static deformation modulus are equivalent and effective. The biggest characteristic of dynamic deformation modulus is that it can reflect the true function of the dynamic stress of the vehicle at high speed. Compare to static deformation modulus on the test principle, test method, test equipment dynamic deformation modulus has obvious advantages. Therefore, the dynamic deformation modulus has become the development direction of the roadbed fill engineering detection technology. In April 2004, the dynamic deformation modulus was formally incorporated into the construction of the railway engineering geotechnical testing procedures (B10102-2004).

Textbook authors Holtz and Kovacs state, "Since the objective of compaction is to stabilize soils and improve their engineering properties, it is important to keep in mind the desired engineering properties of fill, not just its dry density and water content. This point is often lost in earthwork construction control.'[7]

In order to seek more quickly, directly, and nondestructive detection of embankment compaction methods we still need to test and data analysis, so as to realize the rapid detection technology of embankment compaction index.

\section{CONCLUSION}

There are many ways to detect the compaction in the embankment construction. But only to understand the advantages and disadvantages of each method, the scope of application, the operation steps, for different materials, the actual use of the appropriate method to obtain the actual compaction effect of the material. The quality inspection results can reflect the real situation of the project, and provide a good solution and reliable basis for the construction process control and the detection of the quality of compaction after completion. The use of compaction quality testing technology can make us avoid unnecessary duplication of labor, and can save the project cost, to ensure the quality of the project. And save the project cost, to ensure the quality of the project. With the development of science and technology, and the continuous innovation of technology, its progress and development will have a more important theoretical significance and engineering practical value. 


\section{ACKNOWLEDGEMENTS}

The paper was supported by science and technology project of Heilongjiang sanjiang engineering construction administration (HGZL/KY-01).

\section{REFERENCES}

[1] Stratigraphic analyses using GPR[M]. Geological Society of America, 2007.

[2] ECT Team. Soil-Stiffness Gauge for Soil Compaction Control[J]. 2007.
[3] Roesset J M. Nondestructive dynamic testing of soils and pavements[J]. Tamkang JSci Eng, 1998, 1(2): 61-80.

[4] Lytton R L. art[J]. NDT of pavements and backcalculation of moduli, AJ Bush and GY Baladi, Eds, 1989, 1: 7-38.

[5] Asli C, Feng Z Q, Porcher G, et al. Back-calculation of elastic modulus of soil and subgrade from portable falling weight deflectometer measurements[J]. Engineering Structures, 2012, 34: 1-7.

[6] Maher A, Bennert T, Gucunski N. Evaluation of the Humboldt Stiffness Gauge[R]. 2002.

Holtz R D, Kovacs W D. An introduction to geotechnical engineering[M]. 1981. 